\title{
Endotrakealtube med subglottis-sug kan forebygge
} ventilatorassosiert pneumoni

Respiratorbehandling kan redde livet til kritisk syke pasienter . Men selve behandlingen, kombinert med pasientens sykdom eller skade, kan innebære en høy grad av risiko for komplikasjoner og tilleggslidelser.

\section{Forfattere}

Elin Munch

Intensivsykepleier

Sykehuset Østfold - Intensivavdelingen

Anne-Mette Nygaard

Intensivsykepleier

Høgskolen i Østfold - Helse og velferd

Ann-Chatrin Linqvist Leonardsen

Førsteamanuensis

Sykehuset Østfold og Høgskolen i Østfold

\section{Nøkkelord}

\begin{tabular}{l} 
Infeksjon Intensiv NSFLIS Intensivsykepleie Ventilatorassosiert pneumoni VAP \\
\hline Endotrakealtube Subglottis-sug
\end{tabular}


Ventilatorassosiert pneumoni (VAP) er en forholdsvis hyppig komplikasjon i intensivpasientens behandlingsforløp. VAP har en insidens på 10-25 prosent, og en mortalitet på mellom 25-50 prosent. Tidlig diagnose er viktig fordi rask og adekvat behandling kan være livreddende. Retningslinjene for å forebygge VAP som tydelig vektlegger basale smittevernsrutiner må følges. Evidens viser at bruk av endotrakealtuber med subglottis-sug er et godt virkemiddel for å forebygge VAP.

Typiske funn er nye infiltrat på lungene, feber, purulent sekret i luftrøret, unormal økning av antallet hvite blodceller (leukocytose), økt respirasjonsfrekvens, mindre luft som pustes inn og ut per respirasjonssyklus (avtakende tidevolum), økt mengde luft en puster inn eller ut per minutt (økt minuttvolum) og at blodets evne til å ta til seg oksygen blir dårligere (nedsatt oksygenering). Disse tegnene kan komme gradvis eller akutt (2).

\section{Årsaken til VAP}

VAP tenderer mot å ramme de allerede mest kritisk syke og sårbare pasientene på en intensivavdeling (3). Pasienter som har underliggende kronisk sykdom, høy alder, dårlig tannstatus og feil og underernæring er mer utsatt for å utvikle VAP. Alvorlige diagnoser som sepsis, acute respiratory distress syndrome (ARDS), nevrologiske lidelser og alvorlig traume, som ofte krever en langvarig intensivbehandling, øker også faren for VAP (4).

\section{三 «Tuben reduserer de fleste forsvarsmekanismer mot aspirasjon til nedre luftveier."}

Årsaken til VAP er ikke selve respiratoren, men

endotrakealtuben som føres inn gjennom munn eller et nesebor mellom stemmebåndene og ned i luftrøret.

Tuben reduserer de fleste forsvarsmekanismer mot aspirasjon til nedre luftveier. «Tuberelatert pneumoni» er således en bedre, men lite brukt betegnelse (5). 


\section{Forebyggende tiltak}

Intensivsykepleiere har et stort ansvar når det gjelder å forebygge VAP. I tillegg til basale smittevernsrutiner som god håndhygiene for å hindre spredning av bakterier og vedlikehold av ventilatorkretsen, er regelmessig munnstell, bruk av lukket sugesystem, elevert hodeende, minimert sedasjon og tidlig mobilisering, basale forebyggende tiltak. Videre anbefales bruk av endotrakealtube med mulighet for å suge opp sekret nedenfor stemmebåndene (subglottissug) (6).

Til tross for disse anbefalingene er erfaringen at endotrakealtuber med subglottis-sug i liten/varierende grad benyttes ved norske intensivavdelinger. På bakgrunn av denne erfaringen, søker denne artikkelen svar på om endotrakeal tube med subglottis-sug kan være et virkemiddel for å forebygge VAP. Basert på et grundig litteratursøk og gjennomgang av relevante forskningsartikler, presenteres hovedfunnene i denne artikkelen.

\section{Risiko for infeksjon}

Normalt er luftveier og spiserør over stemmebåndene kolonisert av bakterier, mens nedre luftveier under stemmebåndene er sterile. Friske voksne mennesker aspirerer ofte mindre mengder når de sover, men til tross for dette, betinget et friskt lungeparenkym, holder lungene seg fri for mikrobiell kolonisering (7). Øvre og nedre luftveier har normale forsvarsmekanismer, som utgjøres av blant annet slimhinnen og cilier, strupelokket (epiglottis) og hosterefleksen som er medvirkende til å fjerne fremmedlegemer og beskytte organismen mot infeksjon (8). 
Endotrakeal intubasjon i forbindelse med anestesi- og respiratorbehandling påvirker og hemmer effekten av disse normale forsvarsmekanismer, hvorved risikoen for en luftveisinfeksjon øker. Forutgående kolonisering med patogene mikroorganismer i øvre luftveier og etterfølgende mikroaspirasjon er en vesentlig årsak til pneumoni, herunder VAP.

\section{Beskytte luftveiene}

Mikroorganismer når nedre luftveier hovedsakelig ved mikroaspirasjon av sekresjon fra svelget eller sekresjon aspirert til svelget fra magesekken (gastrisk refluks). Mikroorganismer når nedre luftveier også ved direkte forlengelse av en pågående infeksjon, inhalasjon av kontaminerte aerosoler, eller av hematogen spredning av mikroorganismer fra andre infeksjonsfokus (9).

Ved endotrakeal intubasjon føres tuben ned gjennom stemmespalten til spissen er cirka 20-22 centimeter forbi tannrekken. Tubens oppblåsbare mansjett (cuff) hindrer at tuben kommer ut av stilling og beskytter luftveiene mot aspirasjon av mageinnhold (10). Anbefalt cufftrykk er mellom 18 og 25 mm Hg. Målet er å holde cufftrykket lavere enn kapillærtrykket i trakea for å unngå skader på trakea (5).

\section{三 «Biofilmen medvirker til at mikroorganismer blir mer motstandsdyktige overfor antibiotika.»}


Etter nedleggelse av en endotrakeal tube, dannes en biofilm på tubens overflate innen få timer. Biofilmen medvirker til at mikroorganismer blir mer motstandsdyktige overfor antibiotika og kan dermed utgjøre en stor risiko for utvikling av pneumoni. Kolonisering og infeksjonsutvikling kommer an på varigheten av intensivoppholdet, eliminasjon eller endring av bakteriefloraen i nesesvelget - nasopharynx - eller tarm på grunn av antibiotikabehandling, varigheten av antibiotikabehandlingen samt antallet av invasive prosedyrer (11).

\section{Tube med subglottis-sug}

Endotrakealtube forhindrer at åpningen mellom stemmebåndene - glottis - kan lukkes. Et resultat av dette er at intuberte pasienter ikke er i stand til å hoste og fjerne sekresjon på naturlig måte. Derimot samles sekretet i svelget seg over cuffen på tuben, og kan aspireres. Fjerner man sekretet ved hjelp av sug, reduserer man også risikoen for aspirasjon.

Tuber med subglottis-sug (SSS) er designet for å minimalisere risikoen for aspirasjon til lungene og mikro-aspirasjon ved at de har et ekstra lumen som muliggjør fjerning av sekret som legger seg over cuffen. En rekke store helseforetak og guidelines anbefaler bruk av subglottis-sug (12).

Endotrakealtuber med subglottis-sug har en litt større diameter enn tradisjonelle tuber på grunn av sugekanalen. Dette kan øke risikoen for slimhinneskade i trakea. Det er også beskrevet at disse spesialtubene er noe stivere enn tradisjonelle tuber (13).

\section{Kvalitet og utøvelse}


Det er mange forskjellige produsenter som leverer endotrakealtuber, og en nyere studie viser at det er stor forskjell på kvaliteten når det aspireres fra sugekanalen (14). Dette betyr at materialet og designet på cuffen er av stor betydning for å hindre aspirasjon av orofaryngealt sekret. Det er også noe man må ta i betraktning og som har innvirkning på resultatet når man tester om subglottis-sug har effekt.

I tillegg til type tube - tubemateriale - kontinuerlig eller intermitterende sugeprosedyre, bør man også vurdere kontinuerlig cufftrykk-måling når man vil forebygge VAP. Lorente og medarbeidere (15) har sett på kontinuerlig versus intermitterende cufftrykkmåling med henholdsvis tradisjonelle tuber, og tuber med subglottis-sug. De kom frem til at tube med subglottis-sug i kombinasjon med kontinuerlig cufftrykk-måling ga lavest antall ventilatorassosiert lungeinfeksjoner (VARI). I tillegg hevder de at denne kombinasjonen har lavere daglige helsekostnader.

\section{Effekt av subglottis-sug}

Subglottis-sug forebygger VAP. Andre forhold som lengde på intensiv- og sykehusopphold eller mortalitet blir ikke påvirket i særlig grad, noe som også fremkommer av litteraturgjennomgangen som er gjort. En metaanalyse (16) samt en nyere randomisert, kontrollert studie (17) konkluderer begge med at bruk av subglottis-sug (SSS) signifikant reduserer tidlig oppstått VAP og VAP forårsaket av grampositive eller gramnegative bakterier. I tillegg medføre dette kortere intubasjonstid.

Derimot kunne man ikke se noen forskjell på sent oppstått VAP. Gopal og medarbeidere (18) og Hudson og medarbeidere (19) konkluderer med markant reduksjon i antall oppståtte pneumonier hos kirurgiske kardiologiske pasienter med subglottis-sug til tross for kort intuberingstid.

\section{Tuber og mortalitet}


Det finnes også studier som konkluderer med at det ikke er noen forskjell på vanlige tuber sammenliknet med tuber med subglottis-sug når det gjelder forekomst av VAP $(20,21)$. Khorasani og medarbeidere (21) viser til en noe lengre intubasjonstid (1,5 dager) hos SSS-gruppen enn hos kontrollgruppen.

I forhold til varighet på intensivoppholdet er dette omdiskutert: Khorasani og medarbeidere (21), Gopal og medarbeidere (18) og Mao og medarbeidere (24) hevder at det ikke er forskjell på varigheten av intensivoppholdet mellom de to gruppene. Andre hevder at intensivoppholdet er 3-5 dager lengre hos SSS-gruppen enn hos kontrollgruppen $(17,21)$. Hudson og medarbeidere (19) viser derimot til noe kortere intensivopphold hos SSS-gruppen. De samme funnene identifiseres om man studerer lengden på sykehusoppholdet.

Gopal og medarbeidere (18), Mao og medarbeidere (16) og Khorasani og medarbeidere (21) ser ingen forskjell i mortalitet mellom de to gruppene.

Mahmoodpoor og medarbeidere (17) derimot, viser til en forskjell på 10 prosent lavere mortalitet hos SSSgruppen. Hudson og medarbeidere (19) konkluderer med noe lavere 30-dagers mortalitet i gruppen med subglottis-sug.

\section{Komplikasjoner}

Jena og medarbeidere (20) beskriver vanskeligheter med å suge opp sekret som var tjukt, og at sugekanalen ble okkludert av slimhinnen i trakea. Harvey og medarbeidere (13) rapporterer om to tilfeller hvor pasientene fikk store skader på slimhinnen i trakea etter bruk av tube med subglottis-sug. Det ble brukt kontinuerlig negativt sug på -20 mm Hg på begge pasientene, som anbefalt fra leverandørene. Begge pasientene fikk en fistel i spiserøret (øsofagus). 


\section{三 «Intermitterende sug med seks timers mellomrom ble vist som effektivt for å minimere skaderisikoen.»}

Kirurger fastslo - i begge tilfellene - at opphavet til fistlene var akkurat der hvor sugeporten på endortrakealtuben hadde vært. Videre forteller de om en pasient hvor det tilfeldig, under en CTundersøkelse, ble oppdaget at trakealslimhinnen trengte seg inn i åpningen til sugeporten på endotrakealtuben (invaginasjon). Denne pasienten hadde ikke kliniske symptomer på skade i slimhinnen. Studier påpeker også vanskeligheter med å suge opp sekret fordi slimhinnen suger seg fast i sugeåpningen $(17,20)$. Intermitterende sug med seks timers mellomrom ble vist som effektivt for å minimere skaderisikoen.

\section{Erfaringer fra praksis}

Erfaring med disse tubene fra en intensivavdeling på et større sykehus i Norge, viser at de også hadde problemer med å få opp sekret fra tubene. Det var akkurat som om det dannet seg vakuum i sugekanalen. Man valgte derfor å ikke bruke disse tubene den gang (8-10 år siden). Dette problemet støttes i en studie fra Hellas (22) hvor man undersøker hvorfor man ikke lykkes i å aspirere subglottis sekret fra tuber med subglottis-sug.

De opplevde dysfunksjon i så mange som 48 prosent av tubene. Hovedgrunnen til dysfunksjonene var at sugekanalen ble okkludert av at trakealslimhinnen ble sugd fast i åpningen. Ifølge Haas og medarbeidere (23) er det ikke rapportert slike skader ved bruk av intermitterende sug. 
En leverandør av disse produktene i Norge forteller at de ikke har fått rapportert inn slike komplikasjoner. Videre sier de at det er viktig å følge bruksanvisningen, og at man ikke skal bruke krefter ved sugeprosedyren. De nevner også at noen setter inn luft eller $\mathrm{NaCl}$ før de suger. Uansett anbefaler de bruk av subglottis-sug som et virkemiddel for å forebygge VAP.

\section{Redusere VAP-fare}

I studien til Haas og medarbeidere (23) blir det sagt at det er gjort modifikasjoner i form av større diameter på sugekanalen for å redusere okkludering på grunn av slimhinnen, og at aspirasjonslumen er flyttet nærmere cuffen slik at åpningen er mer distansert fra trakealveggen. Dette nevnte ikke leverandør noe om.

Erfaringsmessig kan det være vanskelig å fjerne sekret som legger seg over cuffen ved hjelp av standard sugekateter. I tillegg er sugeprosedyrene ofte en ubehagelig opplevelse for pasientene. De brekker seg og lukker igjen munnen slik at det blir vanskelig å komme til. Samtidig kan det oppstå bradykardier. For å klare å gjennomføre prosedyren må pasienten ofte sederes ned.

Når subglottissekret fjernes ved hjelp av sugekateter er det også fare for skade på slimhinnen i trakea og generell luftveiskontamisjon på grunn av feil sugeteknikk og kontaminering av sugekateter (5). Endotrakealtuber med subglottis-sug synes derfor som et godt virkemiddel for å fjerne sekret, og dermed redusere faren for VAP.

\section{Begrenset erfaring}

Selv om det er stor faglig enighet om at tube med subglottis-sug reduserer antall VAP-tilfeller (16-19), virker det som om dette er den anbefalingen i VAPguidelines som er minst brukt (24). 
Etter en uformell henvendelse til tre intensivavdelinger på Østlandet, virker det som om det er ulik praksis her også. Noen avdelinger bruker tube med subglottis-sug, mens andre ikke gjør det. I en revisjon av britiske «ventilator care bundles» har Baldwin og medarbeidere (24) sendt ut en spørreundersøkelse hvor de blant annet lurer på om det blir brukt tube med subglottis-sug, og hvis ikke - hvorfor?

Under 50 prosent svarte at de brukte subglottis-sug, tross sterke anbefalinger fra Helsedepartementet. Grunnene de oppga for ikke å bruke dette var at de ikke trodde de var kostnadseffektive, var usikre på evidensen, hadde få VAP-tilfeller på avdelingen og hadde begrenset erfaring/bekymring rundt sikkerheten.

\section{Holdningsendring}

Holdninger er ikke noe som forandres på en enkel måte, men er noe man har med seg over tid. Holdninger er derfor relativt varige. Å forandre holdninger krever ofte arbeid som både er tidkrevende og som det koster noe for den enkelte å gjennomføre (25). Forebygging av ventilatorassosiert pneumoni er avhengig av kompetanse og bevissthet fra personalet på intensivavdelingen, samt bevissthet om anvendelsen av kunnskapsbaserte strategier. Begrenset erfaring og usikkerhet er noe mange opplever når det er noe nytt vi ikke har vært borti før.

\section{三 «Intensivsykepleieren bør komme med forslag og vise til relevant forskning på det aktuelle området.»}


I og med at det er intensivsykepleieren som utfører prosedyren med å suge over cuffen er det viktig å kommunisere til anestesilegene at det kan være problematisk å få dette gjennomført.

Intensivsykepleieren bør komme med forslag og vise til relevant forskning på det aktuelle området og på den måten være aktivt med på holdningsendring når det gjelder valg av tuber.

Det er intensivsykepleieren som utfører prosedyren med å suge over tubens oppblåsbare mansjett (cuffen), som tetter til rommet i luftrøret utenfor trakealtuben når denne står på plass. Det er viktig å kommunisere til anestesilegene at det mange ganger kan være problematisk å få gjennomført. Intensivsykepleiere har ikke myndighet til å velge hvilke tuber pasienten skal bruke. Det er legens oppgave. Men det betyr ikke at man ikke kan stille kritiske spørsmål til bruk av tuber, og hvorfor man ikke velger tuber med subglottis-sug.

\section{Implikasjon for praksis}

Akutt og/eller kritisk syke pasienter er i stor grad disponert for infeksjoner, enten med utgangspunkt $\mathrm{i}$ egen normalflora eller utenfra. Spesielt gjelder dette for respiratorpasienter. Den viktigste årsaken til nosokomiale infeksjoner - som for eksempel VAP - er helsepersonellet selv. Retningslinjene for å forebygge VAP som tydelig vektlegger basale smitteverns rutiner må følges.

Litteraturgjennomgang viser stor evidens for at bruk av endotrakealtuber med subglottis-sug er et godt virkemiddel for å forebygge VAP, men at det også kan oppstå komplikasjoner som skader i trakea. Økt vekt på forskning som peker på problemer med designet på trakealtuben og adekvat cufftrykk, gir grunn til å stille spørsmål om det er god medisinsk praksis å fortsette å bruke «standard tuber».

\section{Referanser}


1. Hou P, Baez AA. Mechanical ventilation of adults in the emergency departement. UpToDate. 2017.

Tilgjengelig fra:

https://www.uptodate.com/contents/277 (nedlastet 05.02.2018)

2. Kollef MH. Clinical presentation and diagnosis of ventilators associated pneumonia. UpToDate. 2017. Tilgjengelig fra:

https://www.uptodate.com/contents/1635 (nedlastet 05.02.2018).

3. Klompas M. Prevention of ventilator-associated pneumonia. Expert Review of Anti-infective Therapy. 2010;8(7):791-800. DOI: 10.1586/eri.10.59.

4. Saensom D, Merchant AT, Wara-aswapati N, Ruaisungnoen W, Pitiphat W. Oral health and ventilator-associated pneumonia among critically ill patients: a prospective study. Oral Diseases. 2016; 22(7):709-14. DOI: http://dx.doi.org/10.1111/odi.12535.

5. Bakkelund J, Thorsen BH. Respiratorbehandling (s. 470-525). I: Gulbrandsen T, Stubberud DG, red. Intensivsykepleie. Oslo: Cappelen Damm; 2015.

6. Helsebiblioteket. Ventilatorassosiert pneumoni (VAP) - forebygging - voksne. Oslo: Oslo universitetssykehus;2016. Tilgjengelig fra:

http://www.helsebiblioteket.no/fagprosedyrer/ferdige/ventilatorassosiertpneumoni-vap-forebygging (nedlastet 05.02.2018).

7. Safdar N, Crnich CJ, Maki DG. The pathogenesis of ventilator-associated pneumonia: its relevance to developing effective strategies for prevention. Respiratory care. 2005; 50(6):725-39.

8. Sand O, Sjaastad ØV, Haug E. Menneskets fysiologi. Oslo: Gyldendal Norsk Forlag; 2014. 
9. Oliveira J, Zagalo C, Cavaco-Silva P. Prevention of ventilator-associated pneumonia. Revista Portuguesa de Pneumologia (English Edition). 2014;20(3):152-61. https://doi.org/10.1016/j.rppneu.2014.01.002.

10. Bjerkelund C, Christensen P, Dragsund S, Aadahl P. Hvordan oppnå fri luftvei? Tidsskrift for Den norske legeforening 2010;130(5):507-10. DOI:

10.4045/tidsskr.08.0548.

11. Zolfaghari PS, Wyncoll DLA. The tracheal tube: gateway to ventilator- associated pneumonia. Critical Care. 2011;15(5):310. DOI: 10.1186/cc10352.

12. AACN (American Association of Critical-Care

Nurses). Practice alert, ventilator- associated pneumonia, AACN. 2008;1. Tilgjengelig fra:

http://seeiuc.org/wp-

content/uploads/files/pdf/recursos/profesional/Prevencion_NAVM_AACN.pdf (nedlastet 05.02.2018).

13. Harvey RC, Miller P, Lee JA, Bowton DL, MacGregor DA. Potential mucosal injury related to continuous aspiration of subglottc secretion device. Anesthesiology. 2007;107(4):666-9.

doi:10.1097/01.anes.0000282083.83319.5f.

http://anesthesiology.pubs.asahq.org/article.aspx? articleid=1931349.

14. Mariyaselvam MZ, Marsh LL, Bamford S, Smith ., Wise MP, Williams DW. Endotracheal tubes and fluid aspiration: an in vitro evaluation of new cuff technologies. BMC Anesthesiology. 2017;17(36). DOI 10.1186/s12871-017-0328-0.

15. Lorente L, Lecuona M, Jiménez A, Cabrera J, Mora ML. Subglottic secretion drainage and continuous control of cuff pressure used together save health care costs. American Journal of Infection Control. 2014;42(10):1101-5.

https://doi.org/10.1016/j.ajic.2014.06.028. 
16. Mao Z, Gao L, Wang G, Liu C, Zhao Y, Gu W, Kang H, Zhou F. Subglottic secretion suction for preventing ventilator-associated pneumonia: an updated meta-analysis and trial sequential analysis. Critical Care. 2016;20:353. DOI 10.1186/s13054- 016$1527-7$.

17. Mahmoodpoor A, Hamishehkar H, Hamidi M, Shadvar K, Sanaie S, Golzari SE, Nader ND. A prospective randomized trial of tapered-cuff endotracheal tubes with intermittent subglottic suctioning in preventing ventilator-associated pneumonia in critically ill patients. J Critical Care. 2017;38:152-6. https://doi.org/10.1016/j.jcrc.2016.11.007.

18. Gopal S, Luckraz H, Giri R, Nevill A, Muhammed I, Reid M, Jenkins D. Significant reduction in ventilator-associated pneumonia with the VennerPneuX System in high-risk patients undergoing cardiac surgery: the low ventilator-associated- penumonia study. European Journal of Cardio-Thoracic Surgery. 2015;47(3):92-6. https://doi.org/10.1093/ejcts/ezu483.

19. Hudson JC, McDonald BJ, McDonald JC, Ruel MA, Hudson CC. Impact of subglottic suctioning on the incidence of pneumonia after cardiac surgery: a retrospective observational study. journal of cardiothorac. Vascular Anesthesia. 2015;29(1):59-63. DOI: 10.1053/j.jvca.2014.04.026.

20. Jena S, Kamath K, Masapu D, Veenakumari HB, Ramesh VJ, Bhadrinarayan V, Ravikumar R.

Comparison of suction above cuff and standard endotracheal tubes in neurological patients for the incidence of ventilator-associatcufed pneumonia and in- hospital outcome: A randomized controlled pilot study. Indian Journal of Critical Care Medicine. 2016;20(5):261-6. doi: 10.4103/0972-5229.182196. 
21. Khorasani AG, Shadnia S, Mashayekhian M, Rahimi M, Aghabiklooei A. Efficacy of hi-lo evac endotracheal tube in prevention of ventilatorassociated pneumonia in mechanically ventilated poisoned patients. Scientifica. 2016;5. doi: 10.1155/2016/4901026.

22. Dragoumanis C., Vretzakis GI, Papaioannou VE, Didilis VN, Vogiatzaki TD, Pneumatikos LA. Investigating the failure to aspirate subglottic secretions with the evac endotracheal tube. Anesthesia \& Analgesia. 2007;105(4):1083-5. DOI: 10.1213/01.ane.0000278155.19911.67.

23. Haas CF, Eakin RM, Konkle MA, Blank R. Endotracheal tubes: old and new. Respiratory Care. 2014;59(6):933-55. DOI: https://doi.org/10.4187/respcare.02868.

24. Baldwin F, Gray R, Chequers M, Dyos J. Audit of UK ventilator care bundles and discussion of subglottic secretion drainage. British Association of Critical Care Nurses. 2015;21(5):265-70. DOI: 10.1111/nicc.12146.

25. Håkonsen KM. Innføring i psykologi. Oslo: Gyldendal Akademisk; 2009. 